\title{
Research on the Mechanisms and Disciplines of Clayed Soils Adsorb PAHs in Landfill Leachate
}

\author{
Liu Changli, Wang Cuiling, ZhaO Yuewen, Hou \\ HONGBING, LV DUNYU \\ ${ }^{1}$ Institute of Hydrogeology and Environment Geology, \\ Chinese Academy of Geological Sciences, No.268, \\ Zhonghua North Street, Shijiazhuang, Hebei province, \\ China. (*correspondence: liuchangli@vip.163.com)
}

Abstract: Through the investigation of 831 landfill sites in 306 cities in China, it is found that almost all the fresh leachate contains PAHs, and even the groundwater under the landfill site is polluted. Taking a landfill in North China Plain as an example, the adsorption mechanism and discipline of PAHs in leachate in clayed soil of vadose zone were revealed. The results are as follows:

1.Landfill leachate can improve the absorption capacity of clayed soil to Naphthalene, but has little effect on the absorption to Benzoperylene.

2.In the $0.01 \mathrm{~mol} / \mathrm{L} \mathrm{CaCl}_{2}$ solution, the adsorption regularities of Naphthalene and Benzoperylene in clayed soil accord with a linear equation; In landfill leachate, the Freundlich equation and Lamguir equation are applicable to 2-ring PAH Naphthalene and 6-ring PAH Benzoperylene, respectively.

3.The retardation factors to Naphthalene and Benzoperylene in leachate are related to the concentration of these PAHs, and the relationship is complex. Under the same equilibrium concentration of PAHs in liquid, the retardation factor of clayed soil to Benzoperylene is $1 \sim 8$ times that to Naphthalene.

4. In both adsorption experiments of $0.01 \mathrm{~mol} / \mathrm{L} \mathrm{CaCl}_{2}$ solution and landfill leachate, the initial concentration of Naphthalene and Benzoperylene in the liquid has a good linear relationship with the equilibrium adsorption capacity of clayed soil, and the regulations are similar. 